See Article page 90.

\section{Commentary: When does the burden of treatment outweigh the biological benefit?}

\author{
Alisa N. Blumenthaler, MD, ${ }^{\mathrm{a}}$ and \\ Mara B. Antonoff, MD, FACS ${ }^{b}$
}

Surgical resection remains the primary treatment approach in early-stage, node-negative non-small cell lung cancer (NSCLC). ${ }^{1}$ The current National Comprehensive Cancer Network guidelines do not recommend standard adjuvant chemotherapy after complete resection of node-negative tumors $\leq 5 \mathrm{~cm}$ in dimension, with the exception of tumors exhibiting specific high-risk factors. ${ }^{1}$ Previous studies evaluating cisplatin-based chemotherapy in the adjuvant setting for early-stage NSCLC have demonstrated mixed results in patients with stage IB tumors. ${ }^{2,3}$ Thus, adjuvant therapy for this group has not been widely adopted. On the contrary, randomized trials have demonstrated benefit from tegafur/uracil in the adjuvant setting for Japanese patients, and, thus, this has become the standard of care in Japan for stage IB patients after complete resection. ${ }^{4,5}$

This article by Kunitoh and colleagues ${ }^{6}$ reports the findings of a phase III trial investigating the efficacy of S-1 (tegafur/gimeracil/oteracil), a more potent drug of similar mechanism, compared with tegafur/uracil, as adjuvant chemotherapy for Japanese patients with completely resected node-negative NSCLC tumors $>2 \mathrm{~cm}$ in dimension. The study, which showed no benefit for either drug, used the 5th edition Union for International Cancer Control TNM staging classification system, which limits its clinical applicability in the era of the 8th edition staging system with significant changes in the $\mathrm{T}$ status and overall staging classifications. The relevance and clinical implications of these results are further limited by the fact that neither of

\footnotetext{
From the ${ }^{\mathrm{a}}$ Departments of Surgical Oncology and ${ }^{\mathrm{b}}$ Thoracic and Cardiovascular Surgery, University of Texas MD Anderson Cancer Center, Houston, Tex.

Disclosures: The authors reported no conflicts of interest.

The Journal policy requires editors and reviewers to disclose conflicts of interest and to decline handling or reviewing manuscripts for which they may have a conflict of interest. The editors and reviewers of this article have no conflicts of interest.

Received for publication Aug 26, 2020; revisions received Aug 26, 2020; accepted for publication Aug 28, 2020; available ahead of print Oct 21, 2020.

Address for reprints: Mara B. Antonoff, MD, FACS, Department of Thoracic and Cardiovascular Surgery, University of Texas MD Anderson Cancer Center, 1515 Holcombe Blvd, Houston, TX 77030 (E-mail: MBAntonoff@mdanderson.org). JTCVS Open 2020;4:105-6

2666-2736

Copyright (C) 2020 The Authors. Published by Elsevier Inc. on behalf of The American Association for Thoracic Surgery. This is an open access article under the CC BY-NCND license (http://creativecommons.org/licenses/by-nc-nd/4.0/).

https://doi.org/10.1016/j.xjon.2020.08.018
}

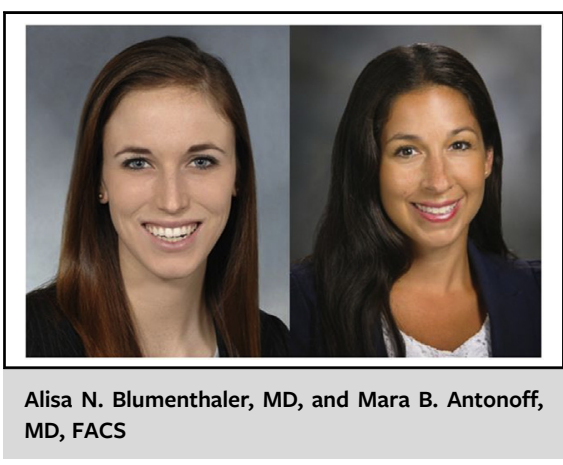

CENTRAL MESSAGE

In patient groups with high

anticipated survival rates, the risk-benefit profile is of utmost importance when considering the use of adjuvant chemotherapy associated with significant toxicities.

the chemotherapy agents included in the study are commonly used for NSCLC outside of Japan. However, this study provides several key extrapolations that are relevant to both broad clinical practice and future studies.

Survival rates were close to $90 \%$ in both treatment groups, which demonstrates the known prognosis in earlystage, node-negative NSCLC. This is an important observation when considering the addition of a treatment modality that is associated with toxicity. Less than $60 \%$ of patients in either group completed the intended therapy, with up to $40 \%$ requiring a dose reduction in the S- 1 group. The cardiopulmonary toxicity of adjuvant S-1 chemotherapy demonstrated in this study echoes similar side effects identified in a meta-analysis of cisplatin-based adjuvant therapy. ${ }^{3}$ The S-1 treatment group saw 3 deaths that were attributed to drug-related cardiac ischemia. The identification of these events reminds us of the vitally important risk-benefit assessment in this early-stage patient population. Among individuals with generally high rates of cancer-related survival, one must consider the worth of a modest improvement (approximately 5\%-6\%) in survival rates afforded by an adjuvant therapy, which carries significant toxicity risks. This is further underscored by the high rate of non-cancer-related deaths in the study by Kunitoh and colleagues as well as a previous meta-analysis of cisplatin-based regimens in which adjuvant chemotherapy was associated with increased rates of non-cancer-related death. $^{3}$ 
Future research focusing on the greatest-risk patients for recurrence may equilibrate the risk-benefit scale when it comes to adjuvant therapy. The National Comprehensive Cancer Network guidelines note that high-risk features such as size $>4 \mathrm{~cm}$, poor differentiation, vascular invasion, wedge resection, visceral pleural involvement, and Nx status may, when taken with the rest of the clinical picture, influence the decision to include adjuvant chemotherapy. ${ }^{1}$ Further consideration, however, should also be given to including quality of life (QOL) and patient-reported outcome measures in future trial designs. ${ }^{7,8}$ These measures are more often used as endpoints in patients with metastatic, incurable disease, and more rarely included in studies of early-stage disease. However, it could be argued that these outcomes are just as important in patients with early-stage disease, as the burden of treatment may not outweigh the potential benefit gained. ${ }^{9,10}$ For treatments found to greatly impact patient-reported QOL, this will become an important aspect of the patient-centered clinical decisionmaking process in a patient with an expected $85 \%$ to $90 \%$ 5-year survival. On the other hand, identified improvements in QOL outcomes with a given treatment will provide additional support to the traditional biological end points of the intervention.

Kunitoh and colleagues should be commended for a well-designed and well-conducted randomized trial and further so for reporting the negative outcome. The secondary results of this study are an excellent reminder to the oncologic community that treatment is not benign, and that the delicate risk-benefit balance is crucial in consideration of any intervention. A patient gains no survival benefit from a chemotherapeutic regimen with intolerable toxicities. Investigators should bear this in mind during future trial design, incorporating patient-reported outcome measures to assess patient perspectives of tested treatment modalities.

\section{References}

1. National Comprehensive Cancer Network. NCCN Clinical Practice Guidelines in Oncology; Non-Small Cell Lung Cancer Version 6.2020. Available at: https:// www.nccn.org/professionals/physician_gls/pdf/nscl.pdf. Accessed August 23, 2020.

2. Strauss GM, Herndon JE II, Maddaus MA, Johnstone DW, Johnson EA, Harpole DH, et al. Adjuvant paclitaxel plus carboplatin compared with observation in stage IB non-small-cell lung cancer: CALGB 9633 with the Cancer and Leukemia Group B, Radiation Therapy Oncology Group, and North Central Cancer Treatment Group study groups. J Clin Oncol. 2008;26:5043-51.

3. Pignon JP, Tribodet H, Scagliotti GV, Douillard JY, Shepherd FA, Stephens RJ, et al. Lung adjuvant cisplatin evaluation: a pooled analysis by the LACE collaborative group. J Clin Oncol. 2008;26:3552-9.

4. Kato H, Ichinose Y, Ohta M, Hata E, Tsubota N, Tada H, et al. A randomized trial of adjuvant chemotherapy with uracil-tegafur for adenocarcinoma of the lung. $N$ Engl J Med. 2004;350:1713-21.

5. Hamada C, Tsuboi M, Ohta M, Fujimura S, Kodama K, Imaizumi M, et al. Effect of postoperative adjuvant chemotherapy with tegafur-uracil on survival in patients with stage IA non-small cell lung cancer: an exploratory analysis from a metaanalysis of six randomized controlled trials. J Thorac Oncol. 2009;4:1511-6.

6. Kunitoh H, Tsuboi M, Wakabayashi M, Okada M, Suzuki K, Watanabe SI, et al. A phase III study of adjuvant chemotherapy in patients with completely resected, node-negative non-small cell lung cancer (JCOG 0707). J Thorac Cardiovasc Surg Open. 2020;4:90-102.

7. Basch E, Abernethy AP, Mullins CD, Reeve BB, Smith ML, Coons SJ, et al. Recommendations for incorporating patient-reported outcomes into clinical comparative effectiveness research in adult oncology. J Clin Oncol. 2012;30:4249-55.

8. Calvert M, Blazeby J, Altman DG, Revicki DA, Moher D, Brundage MD. Reporting of patient-reported outcomes in randomized trials: the CONSORT PRO extension. JAMA. 2013;309:814-22.

9. Zwitter M. Toxicity and quality of life in published clinical trials for advanced lung cancer. Support Care Cancer. 2018;26:3453-9.

10. van der Weijst L, Surmont V, Schrauwen W, Lievens Y. Systematic literature review of health-related quality of life in locally-advanced non-small cell lung cancer: has it yet become state-of-the-art? Crit Rev Oncol Hematol. 2017;119:40-9. 